\title{
Evaluation of Treatment Begun in First Three Months of Life in 184 Cases of Phenylketonuria
}

\author{
FREDERICK P. HUDSON, VIRGINIA L. MORDAUNT, and IRENE LEAHY \\ From Alder Hey Children's Hospital, Liverpool
}

\begin{abstract}
Hudson, Frederick P., Mordaunt, Virginia L., and Leahy, Irene (1970). Archives of Disease in Childhood, 45, 5, Evaluation of treatment begun in first three months of life in 184 cases of phenylketonuria. Data on 184 patients (of whom 15 were treated at Alder Hey Children's Hospital), who began treatment for phenylketonuria (PKU) in the first three months of life, are presented and reviewed. The intelligence and physique of these patients are slightly below average, but the majority do not show evidence of severe mental subnormality such as usually occurs in untreated PKU.
\end{abstract}

In this paper we give details of 15 patients with phenylketonuria treated at Alder Hey Children's Hospital (Liverpool Series), and analyse their progress together with 169 patients treated elsewhere (Full Series). All started treatment before the age of 4 months, because on biochemical evidence they were considered to be phenylketonuric.

Programmes for the early detection and treatment of phenylketonuria (PKU) have been criticized (Bessman, 1966; Birch and Tizard, 1967). Some criticisms refer primarily to the methodology used in reported results of treatment, particularly where the intelligence of early treated cases found through newborn screening or known sibship is compared with that of other patients presenting at a later age because of mental retardation. This paper includes only those patients identified in early infancy through screening tests or because of known familial incidence.

\section{Liverpool Series}

Five cases were ascertained early because of a family history of PKU. Ten were detected by screening tests; one of these tests (referred to as the 'Guthrie Urine Test') is a modification of the bacterial inhibition assay for use with urine impregnated filter paper (E. G. Hall, 1969, unpublished observations).

With the exception of our first patient (Case 1), the diagnosis was always confirmed before the start of treatment by the demonstration of a raised serum phenylalanine level, normal serum tyrosine, and phenyl-

Received 30 June 1969. alanine metabolites in the urine. Biochemical tests at suitable intervals excluded the possibility of a temporary metabolic block, or some alternative explanation for the hyperphenylalaninaemia.

In each case some information about the parental attitude and home environment is given. This is considered essential for the true evaluation of the patient's development.

The psychological tests used were: Wechsler Adult Intelligence Scale (WAIS); Wechsler Intelligence Scale for Children (WISC); Stanford-Binet (L-M) (SB); Merrill-Palmer Scale of Mental Tests (MP); Griffith's Mental Development Scale.

Other abbreviations used in these histories and throughout the paper are: SPA (serum phenylalanine (mg./ $100 \mathrm{ml}$.); DQ (developmental quotient for Griffith's and other standard infant development tests); and IQ (intelligence quotient). Except during the first 30 days of life, age is given in years and months, thus 1-6 for 1 year, 6 months.

Case 1. This boy was born on 14 April 1957. Diagnosis. Sib of known PKU. Ferric chloride test on urine was positive in third week and SPA was reported to be raised but no measurement was given (L. I. Wolff).

Treatment. Diet begun in hospital at 27 days. No problem until age 3-0 when he began taking forbidden food. At 5-3 he was eating cakes and chocolate at school. Discontinued diet at 5-6. Too few SPA levels for mean determinations for first few years of treatment, but they were around $2 \mathrm{mg} .100 \mathrm{ml}$. in the first year, $4 \mathrm{mg} . / 100 \mathrm{ml}$. in the second, $6 \mathrm{mg} . / 100 \mathrm{ml}$. in the third, $2.1 \mathrm{mg} . / 100 \mathrm{ml}$. in the fourth, and $4.6 \mathrm{mg}$./ $100 \mathrm{ml}$. in the fifth.

Physical growth. Centiles at 10-2: height 10th, weight 25 th, head circumference 50th. 
Environment. One retarded PKU sib, IQ under 30. One treated PKU sib (Case 2), IQ 72 at 6-10. Two unaffected sibs, one with IQ $84(\mathrm{SB})$ at 2-4. Mother's IQ 76 (WAIS); father's IQ 105 (WAIS).

$\mathrm{DQ} / \mathrm{IQ}$. Griffith's: 113 at $0-1 ; 107$ at $0-6 ; 84$ at 1-8 ('lack of stimulation at home'); 84 at 2-4. ('Mother does not seem to spend time with him.') MP: 73 at 3-1 ('slow verbally'); 76-86 at 4-2. WISC: 68 at 6-0; 73 at $6-1 ; 79$ at $6-11 ; 73$ at $89 ; 88$ at $8-11 ; 77$ at 10-3 ('verbal somewhat higher than performance').

Treatment was never very satisfactory due to limited rapport with mother who never seemed to understand the importance of diet. Furthermore, this was the first case to receive early treatment in Liverpool, and no dietitian was available. The home environment was poor and provided no intellectual stimulation.

Case 2. Brother of Case 1 (born 23 July 1961).

Diagnosis. Sib of known PKU. SPA 32 at 6 days.

Treatment. Diet begun in hospital at 8 days. No problems adjusting to diet. Began taking normal food at 1-3, and by the age of $1-10$ was eating regular bread every day. At 20 was virtually off dietmother was quite satisfied as he appeared to be doing well. At 2-10 it became obvious that mother was not trying to maintain the diet, and it was abandoned. Mean SPA levels for the first 2 years of life were 3.4 and 8.7. At 1-10 he had a grossly abnormal EEG; at 2-8 it showed evidence of brain damage; at 3-10 was midly dysrhythmic and at 4-8 was normal; at 6- 0 was just outside normal range.

Physical growth. Centiles at 5-11: height 3rd, weight 25th, head circumference 75th.

Environment. One retarded PKU sib, IQ under 30. One treated PKU sib (Case 1), IQ 77 at 10-3. Two unaffected sibs, one with IQ 84 (SB) at $2 \% 4$. Mother's IQ 76 (WAIS); father's IQ 105 (WAIS).

$\mathrm{DQ} / \mathrm{IQ}$. Griffith's: 87 at 1-8. MP: 75 at 4-7. SB: 71 at 6-0. WISC: 72 at 6-10 ('achieved scores of 6-10 on both comprehension and arithmetic but slow on vocabulary and information, possibly due to environment ...').

Mother was even more careless about Case 2's diet than with Case 1 . She allowed him to stop his diet in the third year of life. He also is hampered by a non-stimulating environment.

Case 3. This girl was born on 20 July 1958.

Diagnosis. Sib of known PKU. SPA 18 at 10 days. Treatment. Diet begun in hospital at 9 days of age. In hospital most of the first 18 months of life (mother had to care for retarded PKU sib and husband with cancer of the colon). Short period of gastro-enteritis and megaloblastic anaemia when vitamins were inadvertently omitted. Home for 2 months then admitted again with dermatitis and raised SPA levels. Discharged 4 months later at 2-0. Mean SPA levels for first 5 years of treatment: $1.9,3 \cdot 6,1 \cdot 3,1 \cdot 9,3 \cdot 9$. At 5-6 she was frequently taking forbidden food, and the diet was therefore discontinued.

Physical growth. Centiles at 9-8: height 10th, weight 25th, head circumference 50th. Mother's height 50 th centile.

Environment. One older affected sib: IQ 48 : 10-5. One normal sib, IQ 69 (WISC) at 12-3; anothe्स normal sib IQ 99 (WISC) at 10-11. Mother's I8 86 (WAIS).

DQ/IQ Griffith's: 83 at $1-1 ; 84$ at $1-5 ; 80$ at $1-1 \bar{Q}$ MP: $83-89$ at $2-11 ; 76$ at $3-4 ; 100$ at $4-6$. SB: $79-8$ at $5-9 ; 80$ at $7-11$. WISC: 75 at $6-10 ; 86$ at $7-9 ; 8$ at $8-9 ; 75$ at $9-8$.

A combination of being in hospital and being overtreated during the first years of life may have influenced the IQ and growth pattern. Home environment is one of warm affection, but not intellectually stimulating and with relative poverty.

Case 4. This boy was born on 30 April 1960.

Diagnosis. Positive Phenistix at 31 days. SPA 27 at 31 days.

Treatment. Diet begun in hospital at 32 dayes No problems with diet. Discharged at 38 days and never needed readmission. Mean SPA levels for $\frac{8}{8}$ years of treatment: $2 \cdot 2,4 \cdot 3,5 \cdot 6,8 \cdot 6$, insufficien number, $7 \cdot 6,8 \cdot 0,5 \cdot 0$.

Physical growth. Centiles at 7-10: height 25th weight 25 th, head circumference 50th. Mother height 50th centile.

Environment. No sibs. Mother's IQ 88 (WAIS

$\mathrm{DQ} / \mathrm{IQ}$. MP: 89-94 at 3-0. SB: 93 at WISC: 98 at $5-6 ; 95$ at $7-4 ; 101$ at $8-8$.

An example of an extremely well-managed pheny tonuric. He now understands something of the neee for a special diet and accepts the restrictions withoug fuss. In 1968 he went with a party of schoolchildre to the South of France taking, in prepacked form, specia articles of diet. This demonstration of independence has been most helpful to both child and mother.

Case 5. This boy was born on 28 March 1964.

Diagnosis, Sib of known PKU. SPA 5.9 at 3 days $16 \cdot 6$ at 16 days.

Treatment. Diet begun in hospital at 17 days. $\mathrm{N} \frac{\mathrm{Q}}{8}$ initial problem. Home at $0-2$ and never needed readmission. Mean SPA for first 4 years of treatmento $4 \cdot 8,3 \cdot 0,3 \cdot 0,9 \cdot 4$.

Physical growth. Centiles at 3-10; height 50th? weight 75th, head circumference 50th. Mother's height is 50th centile.

Environment. Two retarded PKU sibs: IQ 45 aP 5-1; IQ 57 at 7-7. Mother's IQ 106 (WAIS); fathe refused to take IQ test.

DQ/IQ. Griffith's: 97 at $0-3 ; 106$ at $0-6 ; 115$ at $0-9 ; 105$ at $1-0 ; 98$ at $1-3 ; 98$ at $1-8$. MP: 100 a $2-1 ; 94$ at 2-9. SB: 84 at 4-0.

Father plays little part in management of the children? Mother is co-operative and remarkably placid considefe ing she has to cope with two retarded enuretic children in addition to this child who in turn is handicappe \& by having two retarded playmates at home. Improve=0 ment may come when he starts school. 


\section{Evaluation of Treatment Begun in First Three Months of Life in Phenylketonuria}

Case 6. This boy was born on 12 June 1964 .

Diagnosis. Negative Phenistix at birth. Positive Guthrie Urine at $\mathbf{4 7}$ days. SPA 53.5 at 48 days.

Treatment. Diet begun in hospital at 48 days. Long history of refusing foods from 2 months old. Dietary treatment abandoned at request of parents at 3-10. Mean SPA levels for first 3 years of treatment were $5 \cdot 4,11 \cdot 0,13 \cdot 2$. Four levels in the beginning of the fourth year of treatment averaged $16 \cdot 2$.

Physical growth. Centiles at 3-9: height 25th, weight 25th, head circumference 25th.

Environment. One unaffected sib reported intelligent and doing well in school. Elder brother is affected with IQ 64 at 9-6. Mother's IQ is 105 on the performance scale of the WAIS. Father refused to take the test.

DQ/IQ. Griffith's: 114 at $0-7 ; 110$ at $1-1$. SB: 109 at 3-10.

From the beginning the boy's mother has questioned the need for nearly every blood test and every facet of treatment and investigation. She has lacked insight into the need for treatment, perhaps because her affected son is only moderately retarded and is socially well adjusted.

Case 7. This boy was born on 24 March 1965.

Diagnosis. Sib of known PKU. SPA $22 \cdot 2$ at 8 days.

Treatment. Diet begun in hospital at 12 days. Soon home and never needed readmission. Mean SPA for first 3 years of treatment $4 \cdot 2,8 \cdot 0,9 \cdot 7$.

Physical growth. Centiles at 3-2: height 75th, weight 90th, head circumference 50th. Mother's height 50th centile; father's height 50th centile.

Environment. Two severely retarded PKU sibs, in institution. Two intelligent unaffected sibs. Mother's IQ 98 (WAIS); father's IQ 112 (WAIS).

DQ/IQ. Griffith's: 110 at 1-5. SB: 100 at 3-6.

His middle-aged parents are extremely delighted with his progress. Their attitude has been relaxed and co-operative. Due to distance from home to hospital, parents take and send blood samples for Guthrie testing, thus saving the need for frequent clinic visits.

Case 8. This girl was born on 14 March 1965.

Diagnosis. Negative Phenistix at 10 days. Positive Guthrie Urine at 29 days. SPA $62 \cdot 5$ at 32 days.

Treatment. Diet begun in hospital at 32 days. Adapted well to diet and discharged at $0-2$, with no readmissions. Mean SPA levels for first 3 years of treatment : $4 \cdot 8,4 \cdot 2$, and $5 \cdot 5$.

Physical growth. Centiles at 3-3: height 50th, weight 75th, head circumference 75th. Mother's height is 50th centile.

Environment. No affected sibs. One unaffected sib IQ 109 at 7-4. Mother's IQ 88 (WAIS); father's IQ 94 (WAIS).

$\mathrm{DQ} / \mathrm{IQ}$. Griffith's: 100 at $0-2 ; 95$ at $0-3 ; 115$ at $0-8$; 113 at $1-1 ; 100$ at $1-7$. SB: 106 at $2-6$.

There has been full co-operation, and no significant problems have arisen.
Case 9. This girl was born on 15 April 1965.

Diagnosis. Positive Phenistix at 19 days. SPA $50 \cdot 0$ at 19 days.

Treatment. Diet begun in hospital on 22nd day. No initial problems and discharged at $0-1$. Refusing some Albumaid at 1-5. Continued difficulty with diet until 3-3, including two periods in hospital for diet re-education. At 3-0 changed to Cymogran which she took well at first, but then refused. Changed to Lofenalac at 3-1, which so far (age 3-10) has been accepted well. Mean SPA levels for first 3 years of life; $6 \cdot 1,7 \cdot 9$, and $8 \cdot 9$.

Physical growth. Centiles at 3-3: height 25th, weight 50th, head circumference 50th. Mother's height $>50$ th centile.

Environment. No full sibs. Five half sibs. Mother's IQ 98 (WAIS); father's IQ 111 (WAIS).

DQ/IQ. Griffith's: 112 at $0-1 ; 108$ at $0-6 ; 116$ at $1-1$. SB: 97 at 2-4.

Though the mother has been co-operative and sensible she has had great difficulty in administering the diet. Eileen has been rebellious and difficult to feed in home and hospital. Since adjustment of diet, her attitude in the clinic has changed from hostile to friendly shyness.

Case 10. This girl was born on 5 April 1965.

Diagnosis. Phenistix dubious positive at 16 days, and at 18 days. Negative at 50 days. SPA 47.0 at 50 days. (The doubtful positive Phenistix was not reported and no further tests were done until the 49th day when the Phenistix was again doubtful.)

Treatment. Diet begun in hospital at 52 days. No initial problem with diet. Discharged at $0-2$ and readmitted for treatment of catarrh and ear infection at 1-10, and antrum washout at 2-2. Microphthalmos in right eye noted at $0-3$. There is complete loss of vision in this eye. Mean SPA levels for first 3 years of treatment were $9 \cdot 2,10 \cdot 8$, and $9 \cdot 7$.

Physical growth. Centiles at 3-3: height 3rd, weight 50th. Mother's height is $>50$ th centile.

Environment. One unaffected sib with IQ 87 (WISC) at 9-3. Mother's IQ 74(WAIS); father's IQ 97 (WAIS).

$\mathrm{DQ} / \mathrm{IQ}$. Griffith's: 83 at $0-3 ; 104$ at $0-8 ; 98$ at $1-2$; 71 at 2-3. MP: 100 at 2-7;63 at 3-8. SB: 62 at 3-8.*

Mother has had problems with administration of the diet and has resorted to force feeding at times. She worries a lot, panics easily, and has poor control over her child.

Case 11. This girl was born on 4 November 1965.

Diagnosis. Positive Phenistix at 21 days. SPA $21 \cdot 6$ at 30 days.

Treatment. Diet begun in hospital at 33 days. Adapted well to diet and was discharged at 0-2. Mean SPA levels for first three years of treatment: $2 \cdot 6,6 \cdot 8$, $8 \cdot 7$.

Physical growth. Centiles at 2-8: height 10th, weight 10th, head circumference 25th. Mother's height is $<50$ th centile.

* One year later IQ 90 (MP). 
Environment. Two retarded PKU sibs, one with IQ 44 at 5-2 and institutionalized; the other with IQ 61 at 7--5. Mother's IQ 98 (WAIS); father's IQ 97 (WAIS).

DQ/IQ. Griffith's : 111 at $0-8 ; 103$ at $1-3 ; 100$ at 1-5; 94 at 1-11. MP: 92 at 2-7.

Mother has accepted the situation well and has few problems with the diet. She is very pleased with the child's progress. The patient is a happy and friendly child.

Case 12. This girl was born on 7 October 1966.

Diagnosis. Negative Phenistix at 39 days. Positive Guthrie Urine at 51 days. SPA 67 at 57 days.

Treatment. Diet begun in hospital at 57 days. Initial adaptation to diet good, but mother not sure of quantities. Admitted at $0-5$ for stabilization of diet. Mean SPA levels for the first two years of treatment were $8 \cdot 1$ and $11 \cdot 6$.

Physical growth. Centiles at 1-7: height 10th, weight 50th, head circumference 50th. Mother's height is 50 th centile.

Environment. 8 normal sibs, 3 who when tested gave the following IQ's: 83 (WISC) at 14-10; 80 (WISC) at $14-0 ; 76(\mathrm{SB})$ at $4-0$. Mother's IQ 88 (WAIS); father's IQ 83 (WAIS).

DQ/IQ. Griffith's : 100 at $0-2 ; 95$ at 0 6; 92 at $1-6$.

Poverty and overcrowding provide problems. Father is a chronic invalid and unemployed. Mother went out to work leaving this child in the care of other members of the family, and dietary control broke down when she was old enough to obtain food for herself. Mother has recently given up working.

Case 13. This boy was born on 17 June 1967 .

Diagnosis. Positive Phenistix at 11 days. SPA 62 at 32 days.

Treatment. Diet begun in hospital at 32 days of age, discharged at $0-2$. Frequent catarrhal infection necessitated antrum washout at 09 . Mean SPA for first year of treatment was $8 \cdot 1$.

Physical growth. Centiles at 1-0: height 90th, weight 25 th, head circumference 50 th.

Environment. One unaffected infant sib born 1968. Mother's IQ 106 (WAIS); father's IQ 129 (WAIS).

DQ. Griffith's : 102 at $06 ; 90$ at $1-3$.

Though father is a university student and both parents are young, they are able to cope with the diet very well. Residence in a university town away from Liverpool prevents regular clinic visits but parents take and send samples of blood for testing.

Case 14. This boy was born on 17 August 1967.

Diagnosis. Raised SPA on routine screening at 4 days of age. SPA 45 at 11 days.

Treatment. Diet begun in hospital at 12 days. Some feeding difficulty at first, but completely settled in 2 weeks. Mean SPA level for first year of treatment was $6 \cdot 9$.

Physical growth. Centiles at 0-9; height 75th, weight 75 th, head circumference 97th. Mother's height $>$ 50th centile.

Environment. No sibs. Mother's IQ 90 (WAIS). DQ. Griffith's : 86 at 1-1.

Healthy, well-developed infant with no problems during the first 18 months of treatment. His mothec has placidly accepted the situation and co-operates fully

Case 15. This boy was born on 17 August 1967.

Diagnosis. Negative Phenistix at 7 days. Positive Phenistix at 20 days. SPA $40 \cdot 0$ at 21 days.

Treatment. Diet begun in hospital at 22 days $\vec{\ominus}$ slight feeding difficulty when switched to solids.. Mean SPA level was $\mathbf{5} \cdot \mathbf{2}$ for first year of treatment.

Physical growth. Centiles at 06 : height 97th weight 97th, head circumference 50th. Mother'융 height is 50 th centile.

Environment. One unaffected sib 2 years olự Mother's IQ 101 (WAIS); father's IQ 114 (WAIS).

DQ/IQ. Griffith's: 102 at $0-1 ; 101$ at $1-1$.

Parents are intelligent and capable, cope well with treatment and have adjusted to the problems involved.

\section{Discussion of Liverpool Series}

Four patients are not yet old enough to undertake a standard intelligence test, but they have achieved. a satisfactory $\mathrm{DQ}$ and are developing normgly as judged by clinical examination. Some dita about the remaining 11 are summarized in 해요 Table. The mean IQ of these older children $88 \cdot 7$ (range 62-109); 16 of their parents wers available for testing and gave a mean IQ of 95.8 (range 88-112). A mean IQ of 89.6 was obtaine $\$$ by 5 of their unaffected sibs, but we prefer not to comment on this owing to the smallness of the sample.

The WAIS results have been reported mainlw for purposes of comparison with previous studiesey The parents were also given a non-verbal test of British standardization (Raven's Progressive Materices), and this suggested a higher intellectual. capacity than that indicated by the WAIS. The same point arises in the testing of the children ip this sample; after 2 years of age they were measure $\phi$ on tests of American standardization, and this could account in part for the lower IQ levels However, since both parents and children were tested on similar scales the over-all pattern o $\$$ results remains consistent. There is no correlation between the mean SPA levels during treatment and the last recorded IQ, perhaps because th series is too small to eliminate the many variable factors influencing development. It is, howevere possible that the levels obtained were nearly a satisfactory, and that a mean SPA below 10 during the first two years of treatment will permit reasone 
TABLE

Summary of Data on 11 Children from Liverpool Series who were Old Enough to Take IQ Tests

\begin{tabular}{|c|c|c|c|c|c|c|c|c|c|}
\hline \multirow{2}{*}{$\begin{array}{l}\text { Case } \\
\text { No. }\end{array}$} & \multirow{2}{*}{$\begin{array}{c}\text { Age treatment } \\
\text { started } \\
\text { (dy.) }\end{array}$} & \multicolumn{5}{|c|}{ Mean Annual SPA Level (mg./100 ml.) } & \multirow{2}{*}{$\begin{array}{c}\text { Latest } \\
\text { IQ }\end{array}$} & \multicolumn{2}{|c|}{ IQ } \\
\hline & & 1 & 2 & 3 & 4 & 5 & & Mother & Father \\
\hline $\begin{array}{r}1 \\
2 \\
3 \\
4 \\
5 \\
6 \\
7 \\
8 \\
9 \\
10 \\
11\end{array}$ & $\begin{array}{r}27 \\
6 \\
10 \\
32 \\
17 \\
48 \\
12 \\
32 \\
22 \\
52 \\
33\end{array}$ & $\begin{array}{l}2 \cdot 0 \\
3 \cdot 4 \\
1 \cdot 9 \\
2 \cdot 2 \\
4 \cdot 8 \\
5 \cdot 4 \\
4 \cdot 2 \\
4 \cdot 8 \\
6 \cdot 1 \\
9 \cdot 2 \\
2 \cdot 6\end{array}$ & $\begin{array}{r}4 \cdot 0 \\
8 \cdot 7 \\
3 \cdot 6 \\
4 \cdot 3 \\
3 \cdot 0 \\
11 \cdot 0 \\
8 \cdot 0 \\
4 \cdot 2 \\
7 \cdot 9 \\
10 \cdot 8 \\
6 \cdot 8\end{array}$ & $\begin{array}{r}6 \cdot 0 \\
1 \cdot 3 \\
5 \cdot 6 \\
3 \cdot 0 \\
13 \cdot 2 \\
9 \cdot 7 \\
5 \cdot 5 \\
8 \cdot 9 \\
9 \cdot 7 \\
8 \cdot 7\end{array}$ & $\begin{array}{c}2 \cdot 1 \\
\text { treatn } \\
1 \cdot 9 \\
8 \cdot 6 \\
9 \cdot 4 \\
16 \cdot 2 \\
- \\
- \\
- \\
-\end{array}$ & $\begin{array}{c}4 \cdot 6 \\
3 \cdot 9 \\
? \\
- \\
- \\
- \\
- \\
-\end{array}$ & $\begin{array}{r}72 \\
72 \\
75 \\
101 \\
84 \\
109 \\
100 \\
106 \\
97 \\
62^{\star} \\
92\end{array}$ & $\begin{array}{r}76 \\
76 \\
86 \\
88 \\
106 \\
105 \\
98 \\
88 \\
98 \\
74 \\
88\end{array}$ & $\begin{array}{r}105 \\
105 \\
- \\
- \\
- \\
112 \\
94 \\
111 \\
97 \\
97\end{array}$ \\
\hline
\end{tabular}

* 1 vear later IQ $90(\mathrm{MP})$.

able intellectual growth. It has been suggested (Hackney et al., 1968) that very strict biochemical control is undesirable, and it might be that such treatment has accounted, in part at least, for the lowish IQ scores of Cases 1 and 3; however, these two children could have been regarded as normal in relation to their family and home backgrounds had they been selected for testing in a large random sample of 'normal' children. Case 6 had the highest mean SPA levels of the series and yet has the highest IQ; it is possible that his biochemical control during the first two years was adequate, and his home environment is good; his mother scored 105 on verbal WAIS testing, and his father, though he refused to be tested, is clearly of average or slightly superior intelligence.

Within this small series there is no evidence to show that the age at which treatment started has had any material effect on the ultimate IQ. Case 2 started at 8 days and has the second lowest IQ; this poor score could, however, be attributed to a number of environmental factors. Case 5 did not start treatment until the age of 52 days and has the lowest IQ, but she was a low birthweight infant with a developmental defect in one eye, and has been handicapped by behaviour problems.

It is clear from this small group of patients that many more careful studies, taking into account the numerous factors that influence child development, are required before firm guidance can be given as to the urgency with which treatment must be started, and the level of SPA which will permit maximum intellectual and physical growth. Details of the home environment make it clear that some of the children have been handicapped by overcrowding, poverty, and lack of intellectual stimulation. We would, however, emphasize that these adverse factors did not preclude a warm affection developing between mother and child, and patients from the poorest homes have not invariably provided the most problems in treatment.

\section{The Full Series}

Details of 184 cases of PKU, all of which started treatment before the age of 4 months, have been collected from the following sources: Liverpool Series 15; PKU Register, Medical Research Council (United Kingdom) 48; PKU Registry, Hereditary Defects Unit (State of California Department of Public Health) 58; and 63 from the literature. Great care has been taken to avoid duplication where cases have been reported more than once. Some authors have generously supplied recent and unpublished information about their patients.

A Table ${ }^{\star}$ has been constructed summarizing data about these patients and recording the following information (where available): Series number, age treatment began, age treatment stopped (where relevant), duration of treatment, beginning or first $\mathrm{DQ} / \mathrm{IQ}$ and age, last or latest $\mathrm{DQ} / \mathrm{IQ}$ and age, growth centiles, mean annual SPA levels; unaffected sibs, IQ and age, affected sibs, IQ and age; parents' IQ, remarks, year of most recent information, number or letter of case in original article, original reference source.

Treatment was begun in the first month of life in 108 cases ( $59 \%$ ), in the second month in 56 cases $(30 \%)$, and in the third month in 20 cases (11\%).

Thirty patients have returned to normal diet, but there is insufficient information to justify comment on the effect of this.

The DQ scores for 148 patients tested before

*Copies may be obtained from Dr. F. P. Hudson, Alder Hey Children's Hospital, Liverpool L 12: 2 AP. 


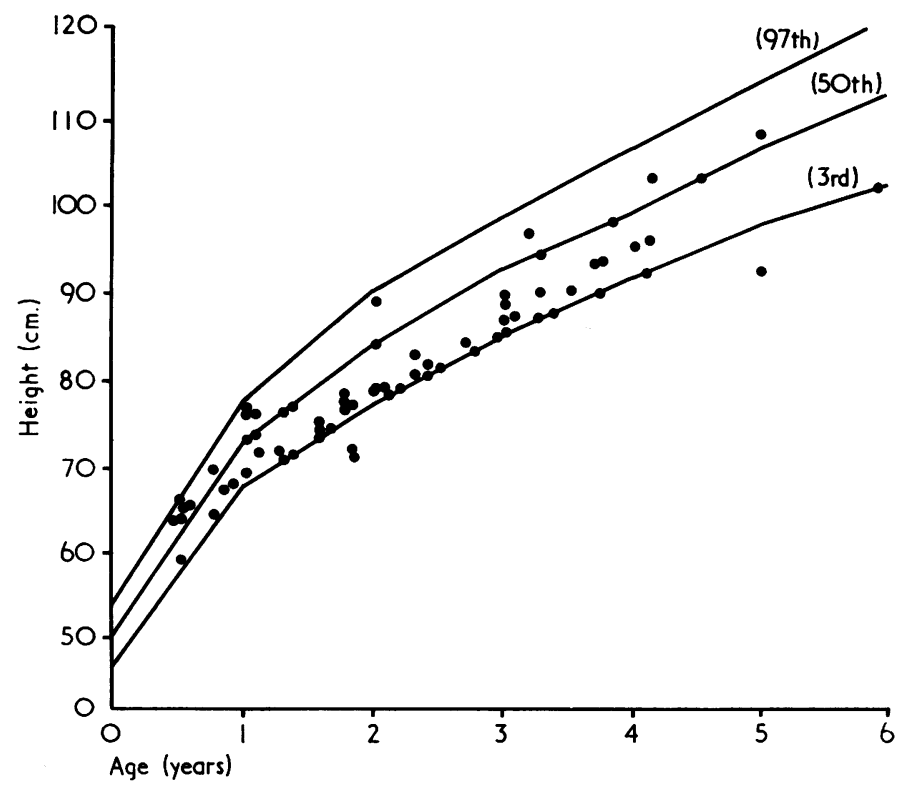

FIG. 1.-Height centiles by age for 69 patients.

the age of $2 \frac{1}{2}$ years range from 49 to 140 , with a mean DQ of $95 \cdot 8$.

The result of an intelligence test taken after the age of $2 \frac{1}{2}$ years, and therefore after at least 2 years and 3 months of treatment, is available for 97 patients out of the $184(53 \%)$. The results range from 50 to 125 , with a mean IQ of $90 \cdot 4$. (Two cases, both with extreme IQ values of 39 and 168, were left out of the calculations, due to insufficient information regarding their individuality.) The mean parental IQ of these 97 patients is $105 \cdot 5$; the mean IQ of their unaffected sibs is

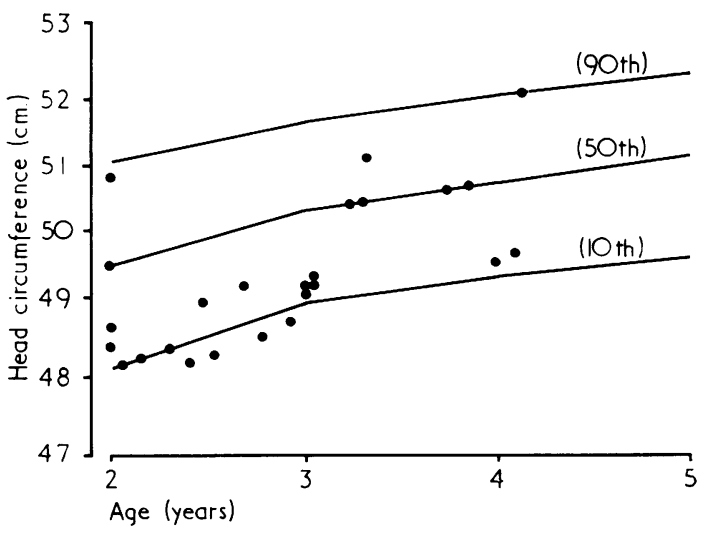

Fig. 2.-Head circumference centiles by age for 25 patients.
$105 \cdot 2$; and the mean IQ of their affected sibsois 53.3. (No distinction is made between treatep and non-treated affected sibs.)

Sixty-five per cent of height measurements 69 patients are between the 3rd and 49th centiles and $4 \%$ are below the 3 rd centile. Skull circum\% ference measurements made after the age of $D$ years are available for 25 patients, and $52 \%$ fal between the 10th and 49th centile. (Information about the patients' weight is included in the Table but measurements of height and head circumferences are probably of greater relevance and are shown in Fig. 1 and 2.)

The degree of biochemical control obtaines during treatment may be judged by the level of. the serum phenylalanine. This information fog the first 4 years of treatment is summarized in Fig. 3.

\section{Discussion}

Proof that early treatment with a low phenyl alanine diet is necessary to prevent mental retardaos tion developing in infants who show the biochemicall characteristics of PKU could only be obtained bu a random controlled trial. In the light of recent clinical experience, as reviewed in this article such a trial would be unethical. Certainly there are a few subjects, with an IQ of 70 or higher and the classical biochemical changes of PKU, who have never received treatment, but the numbe $\bar{E}$ 
reported is very small (Knox, 1966). It is unlikely that many exist undetected in the general population, for estimations of the SPA in 83,000 samples submitted to the Massachusetts Public Health Department for a serological test for syphilis revealed only one case of PKU in an individual thought to be retarded (R. A. MacCready and H. Levy, 1969, personal communication). No case of PKU was detected in another 18,220 normal subjects (Knox, 1966).

The need for careful evaluation of all cases of hyperphenylalaninaemia (Carpenter, Auerbach, and DiGeorge, 1968; Hsia, 1967) is probably recognized by most authors quoted in the Full Series. Evidence to support the diagnosis of PKU is given in detail for the Liverpool Series. Data relating to other patients in the Full Series have been carefully reviewed, and it is likely that the majority, though perhaps not all, represent classical PKU. Other reported cases were considered but excluded because of insufficient evidence, considerable doubt as to the diagnosis, or in some instances, because communication with the author revealed that the original diagnosis could no longer be substantiated.

Taken as a whole, the development of the patients reported in this paper has been satisfactory. It can hardly be doubted that many would have become severely retarded without treatment, yet the mean IQ of these children is only slightly below that of their parents. Their physical growth is a little below the expected mean (see Fig. 1 and 2). Some patients may have been prevented from reaching their maximum physical and mental growth because the biochemical control was too strict (Hackney et al., 1968). Serious malnutrition, deficiency syndromes, and even death have been attributed to the low phenylalanine diet (Brimblecombe et al., 1961; Dodge et al., 1959; Holt, 1963; and Rouse, 1966): these problems should no longer occur, particularly when treatment is controlled by an experienced and enlightened team.

Twenty-seven patients who in the first year of treatment had mean SPA levels between 1.0 and 4.9 developed a mean IQ of $90 \cdot 3$, while a mean IQ of 98.6 was found in 21 patients who in the first year of treatment had mean SPA levels between $5 \cdot 0$ and $9 \cdot 9$. The difference between the means is not statistically significant $(t=1 \cdot 88, p<0 \cdot 10)$ but may give some indication as to the degree of biochemical control needed. The mean SPA by year of treatment and corresponding IQ is, for the first year, 4.9 and $93.5(N=50)$; for the second year, 6.6 and $93.7(\mathrm{~N}=43)$; and for the third year, $6 \cdot 8$ and $91 \cdot 5(\mathrm{~N}=32)$. This might support the general impression that it is undesirable and unnecessary to aim at physiological SPA levels during treatment.

There is a strong positive correlation $(\mathrm{r}=+0 \cdot 464$ $t=3.99, p<0.01$ ) between the first $D Q$ and the most recent IQ available for the same 60 patients. In this paper the distinction between DQ and IQ has been carefully observed; nevertheless, it seems likely that the DQ gives a useful indication of the early stages of the child's progress. It can be argued that IQ results from children

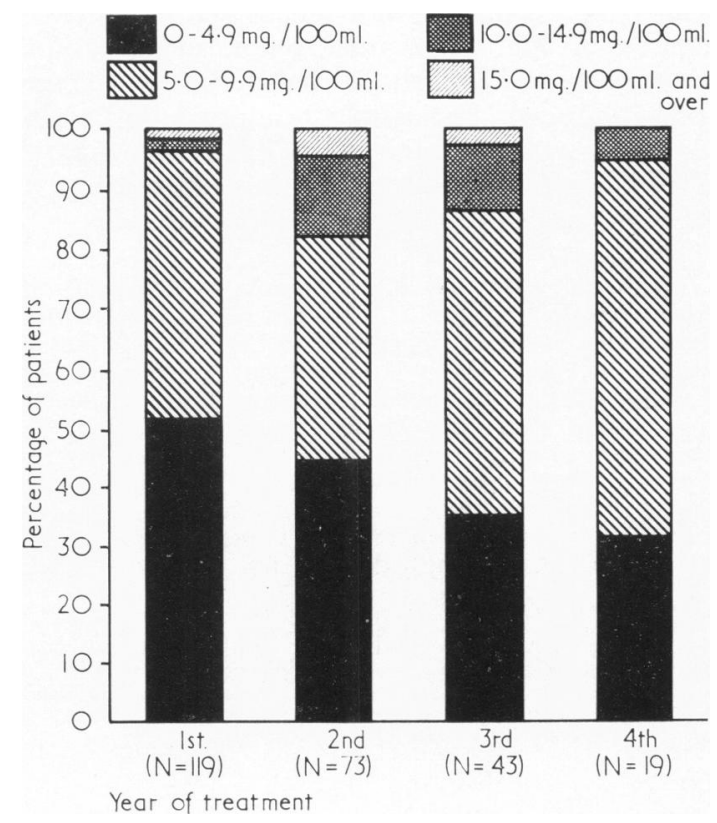

Fig. 3.-Mean SPA levels during treatment shown by year of treatment.

under 5 years of age are of little predictive value, and that the frequent psychological screening given to phenylketonuric children leads to practice effects. When a child behaves intelligently, and at the same time produces a good IQ result, it can be taken as having predictive value. The mean $D Q$ $(94 \cdot 8)$ is higher than the subsequent mean IQ $(90.9)$ for the Full Series in the same group of 60 patients, but this probably reflects the difference in the type of skills being tested, and could also be ascribed to other causes: developing selfconsciousness, negativism, or the influence of adverse cultural values.

While analysis of a large number of patients gives a useful over-all picture, it is also important to consider cases individually. This has only been 
possible with the Liverpool Series where, as has been noted, an apparently poor response to treatment may be attributed to factors other than the metabolic defect.

After a little over one decade of experience, it can be claimed that early and careful treatment of the metabolic defect of PKU by the administration of a low phenylalanine diet is capable of preventing the severe mental retardation often seen in the untreated phenylketonuric. A few patients might develop just as well without treatment, but in our present state of knowledge, they cannot be identified individually in the first 3 months of life. The intelligence and physique of many treated patients is slightly below average. It may, however, be possible to improve on present results by earlier diagnosis, by different standards of biochemical control, or by an improvement in the biological value and palatability of the diet.

The authors are grateful to many paediatricians in Great Britain and the U.S.A. for recent information about their patients particularly to Drs. W. B. Hanley, Robert O. Fisch, Harry A. Waisman, and Miss Helen $\mathrm{K}$. Berry for their generosity in supplying us with recent unpublished data; the Medical Research Council for permission to make use of information collected by the Working Party on Phenylketonuria, and the many paediatricians who supplied this information. We owe special thanks to Dr. George C. Cunningham, for his interest and data supplied from the California PKU
Registry. On the Liverpool Series biochemical tests were supervised by Mr. J. T. Ireland, and some of the psychological reports were prepared by Drs. R. $\frac{\bar{\alpha}}{R}$. Hetherington, J. Graham-White, and J. Schubert, and Mr. P. MacDonald. This work was made possible byona grant from the Institute for Research into Mental Retardation.

\section{REFERENCES}

Bessman, S. P. (1966). Legislation and advances in mediega knowledge-acceleration or inhibition? Pediatrics, 69, $334 \Omega$

Birch, H. G., and Tizard, J. (1967). The dietary treatment $\rho$ f phenylketonuria: not proven? Developmental Medicine âd Child Neurology, 9, 9.

Brimblecombe, F. S. W., Blainey, J. D., Stoneman, M. E. R., $\overrightarrow{\text { and }}$ Wood, B. S. B. (1961). Dietary and biochemical control of phenylketonuria. British Medical fournal, 2, 793.

Carpenter, G. G., Auerbach, V. H., and DiGeorge, A. M. (1968). Phenylalaninemia. Pediatric Clinics of North America, 15, 3तis.

Dodge, P. R., Mancall, E. L., Crawford, J. D., Knapp, J., and PaiRe, R. S. (1959). Hypoglycemia complicating treatment of phenylketonuria with a phenylalanine-deficient diet. $N$ England Fournal of Medicine, 260, 1104.

Hackney, I. M., Hanley, W. B., Davidson, W., and Lindsao, (1968). Phenylketonuria: mental development, behaviff, and termination of low phenylalanine diet. Fournal of Pediatrics, 72, 646

Holt, K. S. (1963). Difficulties and dangers in the management phenylketonuria. Acta Paediatrica. 52, 417.

Hsia, D. Y. Y. (1967). Phenylketonuria 1967. Developmental Medicine and Child Neurology, 9, 531.

Knox, W. E. (1966). Phenylketonuria. In The Metabolic Basis $f$ Inherited Disease. p. 258. Ed. by J. B. Stanbury, J. ब3. Wyngaarden, and D. S. Fredrickson. McGraw-Hill, New York.

Rouse, B. M. (1966). Phenylalanine deficiency syndrome. of Pediatrics, 69, 246.

Correspondence to Dr. F. P. Hudson, Alder Children's Hospital, West Derby, Liverpool L12 